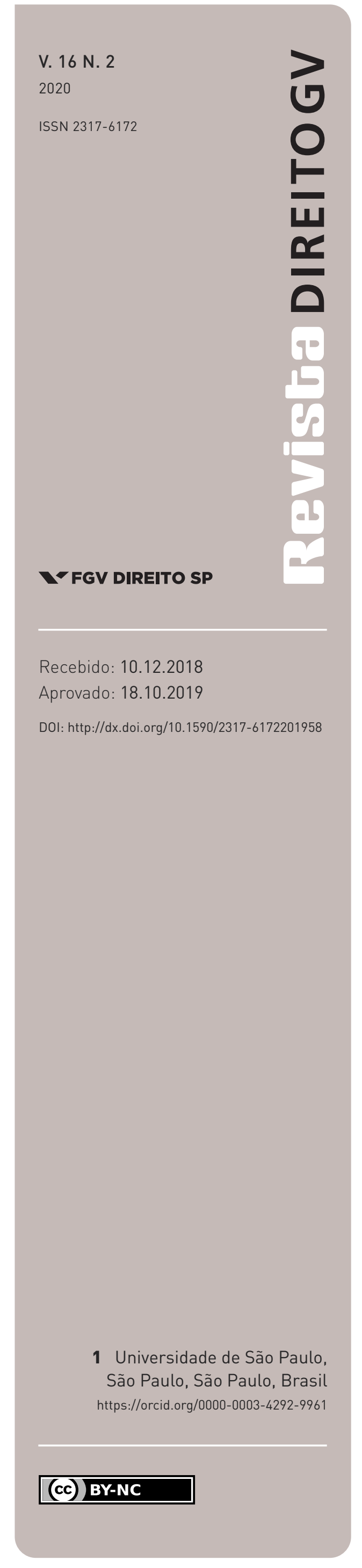

\title{
Relativismo moral em Kelsen: do juspositivismo à democracia
}

\author{
MORAL RELATIVISM IN KELSEN: FROM POSITIVISM TO DEMOCRACY
}

Ana Luiza Rodrigues Braga ${ }^{1}$

\section{Resumo}

Este artigo analisará as relações entre a teoria da democracia e a teoria do direito de Hans Kelsen. Na primeira parte, será demonstrado de que modo o relativismo moral consiste em um pressuposto filosófico de toda a obra de Kelsen. Em seguida, será detalhada a relação do relativismo com as suas concepções de ciência do direito e de ciência política, argumentando-se que é possível enxergar essas duas vertentes da obra kelseniana como partes de um único projeto teórico. Explicar-se-á de que maneira o conceito de democracia defendido por Kelsen, pautado em um esvaziamento axiológico em prol do procedimento, se adequa tanto ao seu pressuposto relativista quanto a suas aspirações científicas. Ao fim, a conclusão é de que para Kelsen a pureza metodológica na abordagem da política e do direito representa, por si própria, um valor democrático, de forma que também por isso a democracia é concebida por Kelsen sob um viés exclusivamente procedimental, apontando para um método específico de criação do direito que concebe os valores da liberdade e da igualdade não como fins, mas como engrenagens da máquina democrática.

\section{Palavras-chave}

Hans Kelsen; positivismo jurídico; ciência política; democracia; relativismo moral.

\section{Abstract}

This article will examine the relationship between Hans Kelsen's theory of law and theory of democracy. In the first part, it will be demonstrated how moral relativism consists in a philosophical presupposition of the whole work of Kelsen. Then it will be detailed the relation of moral relativism to Kelsen's conceptions of law and political science, arguing that it is possible to see these two aspects of the kelsenian work as parts of a single theoretical project. It will be explained how the concept of democracy defended by Kelsen, based on axiological emptying, fits both its relativistic assumption and its scientific aspirations. At the end, the conclusion is that, for Kelsen, methodological purity represents itself a democratic value. As a result, democracy is seen through an exclusively procedural theoretical point of view that conceives the values of freedom and equality not as ends, but as gears of the democratic machine.

\section{Keywords}

Hans Kelsen; legal positivism; political science; democracy; moral relativism. 


\section{INTRODUÇÃO}

O tema do relativismo moral é uma excelente porta de entrada para que se compreenda a concepção de mundo que subjaz a toda a obra de Kelsen, seja nos aspectos concernentes à sua teoria do direito, seja nas suas reflexões políticas. Pode-se mesmo afirmar que, se existe uma inspiração filosófica que está por trás de cada um dos escritos de Kelsen, ela consiste no relativismo moral. A esse respeito, o próprio Kelsen afirma estar convencido de que as oposições entre teorias jurídicas são, no fundo, oposições entre visões de mundo, de tal modo que já em sua obra seminal de 1911, Problemas fundamentais da doutrina de direto público, ele afirma a necessidade e utilidade em "descobrir as relações existentes entre o pequeno mundo das ciências jurídicas e o grande mundo, aquele do sistema filosófico universal” (KELSEN, 1997, p. 13).

Tendo em vista que o relativismo é uma corrente de pensamento multifacetada, procuraremos alcançar dois objetivos principais com este artigo. O primeiro deles é situar o relativismo kelseniano no interior de um panorama filosófico mais amplo, explicitando suas raízes e peculiaridades. O segundo objetivo é explicitar a relação do relativismo com as concepções de ciência do direito e de ciência política em Kelsen. Com isso, procuraremos demonstrar que a teoria jurídica e a teoria democrática de Hans Kelsen consistem em duas partes de um grande e único projeto, cuja marca distintiva está na ideia de ciência como visão de mundo.

Com essa defesa, opomo-nos ao argumento de alguns intérpretes de Kelsen, como Alfonso Ruiz Miguel, para quem o autor da Teoria Pura do Direito, ao formular sua defesa da democracia, teria deixado de exigir da ciência política a mesma pureza valorativa demandada para a ciência do direito. Segundo essa interpretação, Kelsen teria traído seu rigor metodológico na sua abordagem da democracia.

Discordando dessa visão, demonstraremos que a abordagem da democracia em Kelsen não escapa do seu ideal de pureza valorativa, embora a metodologia aplicada a esse objeto seja, de fato, pautada por um critério de avaliação próprio, que ele defende ser mais adequado à análise dos sistemas políticos. Também nesse contexto, defenderemos que a exigência kelseniana de uma abordagem científica avalorativa sobre o objeto político e o objeto jurídico se justifica exatamente em razão do relativismo moral.

Por fim, demonstraremos como o conceito de democracia defendido por Kelsen, pautado em um esvaziamento axiológico em prol do procedimento, se adequa, de um lado, ao seu pressuposto filosófico relativista e, de outro, às suas aspirações científicas.

\section{KELSEN E O RELATIVISMO MORAL}

Antes de apresentar de maneira mais detalhada o sentido que o próprio Kelsen confere à terminologia do relativismo de valores morais, é necessário demonstrar o lugar desse tópico no interior do projeto que a modernidade ${ }^{1}$ apresentou para a ciência e para a filosofia.

\section{$\bullet \bullet$}

1 Chamaremos de modernidade filosófica, para os fins deste trabalho, o período da filosofia moderna que 
Para compreender as raízes do relativismo é necessário remontar a uma das grandes questões científicas e filosóficas, consistente na investigação das relações entre aparência e realidade, entre a forma como percebemos o mundo e aquilo o que ele realmente é (MICHELON JR., 2004, p. 39). Esse problema é considerado clássico, pois remete às origens da filosofia, quando Tales de Mileto - pensador ao qual se atribui o início da filosofia grega (REALE e ANTISERI, 1990, p. 29) - procurava identificar o princípio imutável por trás de todas as coisas mutáveis e perenes. Para Tales, a água era a substância essencial de tudo aquilo que percebemos por nossos sentidos. A respeito dessa primeira incursão naquilo que se chama atualmente de filosofia da physis, explicam Giovanni Reale e Dario Antiseri (1990, p. 31):

Com Tales, o logos humano rumou com segurança pelo caminho da conquista da realidade em seu todo (a questão do princípio de todas as coisas) e em algumas de suas partes (as que hoje constituem o objeto das "ciências particulares", como hoje chamamos).

Contudo, Tales de Mileto era um "naturalista" no sentido antigo do termo, de modo que ele não compreendia a natureza no sentido moderno e contemporâneo, mas a concebia no "sentido original de realidade primeira e fundamental” (REALE e ANTISERI, 1990, p. 30). Nesse sentido original, "a sua água” coincidia com a própria noção de Deus ou, em outros termos, aquilo que existe desde sempre e que, por isso, não fora criado por nenhuma outra força superior.

A ressalva quanto ao sentido moderno de compreensão das coisas, feita por Reale e Antiseri (1990, p. 30), é indicativa de uma grande mudança de mentalidade, fruto de drásticas transformações na maneira de conceber e fazer a filosofia. ${ }^{2}$ Dito de outro modo: enquanto a

se inicia com Descartes e cuja manifestação mais recente se encontra na obra de Wittgenstein (SCRUTON, 2008, p. 15). Explicitando o mesmo recorte teórico de modernidade, vide Michelon Jr. (2004).

2 A exemplo do contraste entre a mentalidade grega e a mentalidade moderna, é ilustrativo aquilo que explica Alfred Whitehead: "O gênio grego era filosófico, claro e lógico. Os homens desse grupo estavam primordialmente respondendo a questões filosóficas. Qual é o substrato da natureza? O fogo, a terra, a água ou a combinação de dois deles, ou dos três? Ou é um mero fluxo, irredutível a qualquer material estável? A matemática despertou grande interesse entre eles. Inventaram sua regra geral, analisaram suas premissas e fizeram notáveis descobertas de teoremas mediante uma rígida fidelidade ao raciocínio dedutivo. A mente deles estava contaminada de uma ávida generalidade. Exigiam ideias claras, evidentes e raciocínio exato com base nelas. Tudo isso foi muito bom, foi genial, foi um trabalho preparatório ideal. Não foi, porém, ciência conforme a entendemos. A paciência da observação minuciosa não teve nem de longe destaque. O gênio deles não estava suficientemente apto para o estado de desordenada incerteza imaginativa que precede, com sucesso, generalizações indutivas. Eram pensadores lúcidos e raciocinadores claros" (WHITEHEAD, 2006, p. 20). 
pergunta filosófica permanece a mesma, os métodos para respondê-la foram irremediavelmente transformados pela tradição da chamada filosofia moderna. Em suma: "há uma diferença entre as reações antigas e modernas ao mesmo estímulo" (WHITEHEAD, 2006, p. 174).

A filosofia moderna tem origem congenial com a ciência moderna e contemporânea. $\mathrm{O}$ desenvolvimento espantoso da ciência a partir do século XVI deu novas tonalidades à mentalidade humana, inaugurando uma nova metodologia científica e, mais tarde, filosófica: ao racionalismo metafísico dos gregos, herdado pelos escolásticos medievais, os pensadores modernos opuseram uma abordagem empirista sobre "os fatos brutos e inflexíveis" (WHITEHEAD, 2006, p. 15), de modo que a observação e o experimento passaram a consistir nas grandes autoridades metodológicas.

Nesse contexto, o grande problema que intrigava os pensadores modernos, especialmente a partir de Descartes, estava em responder: como diferenciar aquilo que eu vivencio com os meus sentidos daquilo que de fato existe no mundo dos "fatos brutos e inflexíveis"? Como separar o conhecimento subjetivo (aquilo que percebo em virtude de uma disposição interior) do conhecimento objetivo (aquilo em que consiste o mundo como ele realmente é)? Na sua tentativa de diferenciar o mundo exterior do mundo interior, Descartes e outros pensadores, como Galileu, buscaram estabelecer uma diferenciação entre aquilo que se pode chamar de qualidades primárias e qualidades secundárias (MICHELON JR., 2004, p. 47). As primeiras consistiriam na genuína qualidade das coisas, tais como aquelas ligadas à substância material mensurável (Galileu) ou que poderiam ser detectadas por mais de um sentido (Descartes). As segundas, por sua vez, seriam aquelas consistentes em percepções - como cor e odor -, sensações - como a dor - e emoções.

Para Descartes, apenas as qualidades primárias poderiam ser objeto da ciência moderna, já que as qualidades secundárias, presentes no mundo interior e subjetivo, são a) insuscetíveis de engano, quando se trata de proposições que descrevem o meu mundo interior: "não é possível que eu esteja enganado sobre o que eu estou vendo ou pensando (embora eu possa estar enganado naquilo em que estou vendo ou pensando)" (MICHELON JR., 2004, p. 50); b) insuscetíveis de investigação científica, quando se trata de proposições que descrevem o mundo interior de outras pessoas: "sem que existam critérios seguros para decidir sobre a dor de outra pessoa, não haveria como verificar a veracidade da proposição que a expressa (não é possível conhecer o valor de verdade desta)" (MICHELON JR., 2004, p. 51).

Com a enorme influência dessa mentalidade cartesiana no ambiente científico e filosófico subsequente, o âmbito da investigação científica ficou reduzido ao mundo exterior, cabendo à filosofia se retirar para a subjetividade (WHITEHEAD, 2006, p. 177). ${ }^{3}$ A ciência, então,

3 Em face da afirmação de Whitehead (2006, p. 177) de que a filosofia se retirou para o âmbito da subjetividade, poder-se-ia objetar que a modernidade filosófica também apresenta exemplos de tentativas de 
passou a ocupar a tarefa de examinar a realidade, ao mesmo tempo que foi abalando, pouco a pouco, as crenças tradicionais que se tinha em religião, política e moralidade, questões que ficaram aprisionadas no âmbito da primeira pessoa, em que qualquer problematização objetiva não faz sentido.

A princípio, no tocante à moralidade, até se nutriu a ideia de uma "ciência moral", 4 impulsionada por uma espécie de otimismo newtoniano, mas logo essa esperança pareceu esvanecer. Afinal, se, a exemplo da moralidade, tudo aquilo que não está atado aos "fatos brutos e inflexíveis", isto é, às qualidades primárias das coisas, é insuscetível de comprovação, torna-se impossível conhecer uma verdade objetiva a esse respeito: tudo o que existe são verdades morais subjetivas, ou seja, válidas apenas no mundo interior de cada pessoa. Tudo o que resta são verdades relativas.

Em outros termos, para um filósofo cético, a obtenção do conhecimento moral simplesmente não é possível, já que a metodologia do cientificismo moderno não pode ser aplicada nessa seara. Para o cético moral, em suma, todos os discursos axiológicos são dotados de igual peso, de modo que ele não tem como aceitá-los ou recusá-los, cabendo-lhe somente, como prova de fidelidade à metodologia cartesiana, suspender seu juízo sobre as diversas alternativas morais existentes.

A respeito desse processo mental implícito no ceticismo, Oswaldo Porchat Pereira (1987, p. 40) explica:

[...] ao dizer que suspende o juízo, o cético quer simplesmente significar que é incapaz de dizer no que deve acreditar ou não acreditar dentre quantas coisas se lhe apresentam, já que lhe aparecem iguais as alternativas no que respeita à sua credibilidade ou não credibilidade.

É precisamente isso - em termos, aliás, muito semelhantes - o que defende Kelsen, quando afirma que "quem considera inacessíveis ao conhecimento humano a verdade absoluta e os valores absolutos não deve considerar possível apenas a própria opinião, mas também a opinião alheia” (KELSEN, 2000, p. 105), ou, ainda:

descrição de uma objetividade ética em termos de uma psicologia moral, como é possível identificar na obra de David Hume, por exemplo. A abordagem de Hume, contudo, pode ser inserida no âmbito daquilo que, na nota seguinte, chamamos de "naturalismo", tendo em vista que propõe uma "filosofia moral" do homem que parte de "observações empíricas sobre a mente humana", dando ênfase no hábito e no instinto como guias (SCRUTON, 2008, p. 156).

4 Um exemplo de tentativa em desenvolver uma espécie de "ciência moral” está na corrente de pensamento que se pode chamar de naturalismo ético. Conforme explica Roger Scruton (2008, p. 141): "Naturalismo é a teoria de que o ideal da vida boa deve ser derivado não de um preceito divino, mas de uma descrição da natureza humana. Tal teoria visa demonstrar que o mal é contra a natureza, enquanto o bem a realiza”. 
O problema dos valores é, antes de tudo, o problema dos conflitos de valores. E esse problema não poderá ser solucionado com os meios do conhecimento racional. A resposta às questões que aqui se apresentam é sempre um juízo, o qual, em última instância, é determinado por fatores emocionais e possui, portanto, um caráter subjetivo. Isso significa que o juízo só é válido para o sujeito que julga, sendo, nesse sentido, relativo. (KELSEN, 2001, p. 6)

A partir dos trechos destacados anteriormente, ${ }^{\mathbf{5}}$ é possível caracterizar o relativismo kelseniano como uma espécie de metaética, no mesmo sentido em que a Teoria Pura do Direito é considerada uma metaciência do direito. Em sua defesa do relativismo, Kelsen não ignora que as pessoas pautam suas vidas em regras morais, mas busca destacar que não há qualquer metodologia científica capaz de conferir a esses valores uma validade intersubjetiva.

É possível identificar, desse modo, o relativismo axiológico de Kelsen como uma espécie particular de ceticismo moral epistemológico (DIAS, 2010, p. 145), isto é, que remete à impossibilidade da averiguação de uma verdade objetiva (epistemologia) nessa seara. ${ }^{6}$

Essa espécie de ceticismo epistemológico, cuja denominação para Ronald Dworkin ${ }^{7}$ vem sob o título de ceticismo externo do estatuto (DWORKIN, 2012, p. 62), caracteriza-se pela negativa em conferir aos juízos morais qualquer pretensão de objetividade, pelo fato de que eles não podem ser caracterizados e descritos enquanto fatos morais. Para Dworkin (2012, p. 44), os

5 Há muitas outras passagens da sua obra em que Kelsen deixa antever seu ceticismo epistemológico. A esse respeito, vide ensaios da coletânea: Kelsen (2001).

6 A diferenciação terminológica entre relativismo e ceticismo, assim como a subdivisão interna dessas categorias, é algo que rende muitas discussões no âmbito da filosofia. Alfonso Ruiz Miguel, por exemplo, diferencia três espécies de relativismo ético: o relativismo descritivo, o relativismo normativo e o relativismo metaético ou epistêmico. Conforme explica Alfonso Ruiz Miguel, o relativismo descritivo tão somente reconhece "o fato trivial do pluralismo ideológico", afirmando que diversas culturas podem manter critérios morais distintos e mesmo contraditórios; o relativismo normativo, por sua vez, defende que critérios morais podem ser válidos ou corretos não apenas do ponto de vista dos participantes, mas também do observador, de tal modo que tudo depende do critério imposto em determinada cultura - trata-se, para Alfonso Ruiz Miguel, de uma “espécie de concepção desportiva da ética política”; o relativismo metaético, por fim, consiste na ideia de que "não há nenhum supracritério racionalmente válido que permita decidir de maneira objetiva aquilo que é correto ou incorreto moralmente". Como é possível perceber, Kelsen se encaixa nesta última categoria (RUIZ MIGUEL, 2016, p. 13-14, tradução livre).

7 Não pretendemos aqui entrar em todos os detalhes da classificação que Dworkin realiza dos tipos de ceticismo. De todo modo, é útil buscar traduzir especificamente aquilo que o autor americano chama de ceticismo do estatuto (DWORKIN, 2012, p. 62), porque esta, de fato, consiste na postura compartilhada por Kelsen. 
céticos do estatuto "distinguem a descrição de outras atividades, como tossir, expressar emoção, dar uma ordem ou assumir um compromisso, e afirmam que exprimir uma opinião moral não é descrever, mas antes algo que pertence ao último grupo de atividades”.

É exatamente imbuído desse espírito cético que Kelsen (1955, p. 17) realiza a seguinte afirmação:

O relativismo filosófico [...] enquanto empirismo (ou positivismo) antimetafísico insiste em uma clara separação entre realidade e valor e faz uma distinção entre proposições sobre a realidade e juízos de valor genuínos que, em última instância, não são baseados em uma cognição racional da realidade, mas nos fatores emocionais da consciência humana, nos desejos e temores do homem. Uma vez que não remetem a valores imanentes a uma realidade absoluta, não podem estabelecer valores absolutos, mas apenas relativos. Uma filosofia relativista é decididamente empirista e racionalista e, em decorrência disso, tem uma franca inclinação ao ceticismo.

Kelsen, portanto, faz parte de um grupo de filósofos modernos, entre os quais se destaca David Hume, que acredita que nossos princípios e normas morais estão baseados, em última instância, em desejos e preferências estritamente subjetivos. É isso, aliás, que permite Hume defender que não deveríamos “achar que 'certo' e 'errado' são propriedades inerentes às coisas, independentemente de nossa disposição a aprová-las ou desaprová-las" (SCRUTON, 2008, p. 169), de tal modo que vício e virtude são simples percepções da mente, identificados conforme os desejos e interesses antecedentes de cada pessoa. De maneira muito semelhante, Kelsen (2001, p. 23) assenta que

[...] o juízo, por meio do qual algo é declarado como justo, nunca poderá ser emitido com a reivindicação de excluir a possibilidade de um juízo de valor contrário. Justiça absoluta é um ideal irracional. Do ponto de vista do conhecimento racional existem somente interesses humanos e, portanto, conflito de interesses. Para solucioná-los, existem apenas dois caminhos: ou satisfazer um dos interesses à custa do outro, ou promover um compromisso entre ambos.

Além de ser claramente legatário de uma herança metodológica na qual está enraizada toda uma história da filosofia ${ }^{8}$ o relativismo kelseniano também foi influenciado diretamente pelas novidades científicas de seu tempo, com especial atenção para aquelas que provinham

8 Oswaldo Porchat Pereira é certeiro ao identificar que, considerando esses pressupostos como algo implícito, deixamos de identificá-los com a história da filosofia precedente: "Tão habitual se tornou essa postura 
da psicanálise e da antropologia. Na postura relativista de Kelsen, a marca de Freud se faz sentir de maneira forte, ${ }^{9}$ especialmente se for considerada a complexidade que a descoberta do inconsciente conferiu ao estudo da mente humana. Para Kelsen, seguindo a esteira de Freud, todas as visões morais a respeito do mundo são desencadeadas, em última instância, por elementos psicológicos essencialmente individuais e conflitantes (HERRERA, 1997, p. 253), que determinam visões de mundo e decisões práticas situadas sobre uma base de determinações imperscrutáveis para a ciência objetiva.

Visto por esse ponto de vista, dentro do espectro do relativismo, é igualmente correto classificar Kelsen como um relativista moral subjetivo (DIAS, 2010, p. 145). De fato, sua defesa do relativismo passa menos por um atestado histórico ou cultural das diferentes visões éticas e mais por uma constante defesa de que é a existência de uma pluralidade de indivíduos que está no centro da grande variedade de valores morais.

A questão que se impõe agora, situado o relativismo kelseniano no espectro mais amplo da história da filosofia, é a de investigar de que maneira essa concepção de mundo se relaciona aos projetos juspositivista e democrático de Hans Kelsen. Em outras palavras, é preciso perscrutar de que modo a tese do relativismo está atada ao positivismo jurídico kelseniano e, de igual maneira, por qual motivo Kelsen considera que "o relativismo é congenial à democracia, não como uma fundamentação, mas como uma justificação" (PECORA, 2015, p. 114). Essa investigação será especialmente útil para demonstrar a maneira pela qual as obras jurídicas e políticas de Hans Kelsen mantêm estreita relação entre si e representam um todo coerente.

\section{RelATIVISMO: DO JUSPOSITIVISMO À DEMOCRACIA}

\section{I. O RELATIVISMO NA TEORIA DO DIREITO}

A marca do ceticismo de Kelsen sobre o seu projeto juspositivista se faz sentir já na escolha da nomenclatura escolhida pelo jurista: para Kelsen, seu intento teórico não corresponde a um exercício de filosofia do direito, mas de teoria geral do direito (HERRERA, 2010, p. 99).

Essa diferenciação se explica pelo fato de que Kelsen está interessado em promover uma ciência jurídica, destinada a descrever a estrutura dos ordenamentos jurídicos positivos tal

metodológica e tão natural ela nos parece que não vislumbramos, à primeira vista, como se poderia assumir alguma outra, sem incorrer em um dogmatismo ingênuo e pouco crítico. De tal modo se incorporou à nossa tradição filosófica esse modo de ver as coisas que muitas filosofias nem mesmo se demoram em considerá-lo e esclarecê-lo, menos ainda em discuti-lo" (PEREIRA, 1987, p. 34).

9 A influência da teoria psicanalítica freudiana está espraiada por muitos aspectos da obra de Kelsen, notadamente naqueles concernentes à sua teoria política e à sua teoria do Estado. 
como eles existem. Assim, em contraposição à teoria geral do direito, concebida por Kelsen como a verdadeira ciência jurídica, estaria uma filosofia do direito, responsável por se ocupar de questões como a justiça, destinadas a conferir ao ordenamento jurídico uma justificação externa, fora da norma positiva - seja em uma ordem moral metafísica (caso do jusnaturalismo), seja em fatos do mundo (caso do pseudojuspositivismo). Embora tal diferenciação conceitual possa parecer, em um primeiro olhar, uma arbitrariedade por parte de Kelsen (DIAS, 2010, p. 126), o fato é que ela é, como demonstrado, uma decorrência do tipo de pensamento marcadamente moderno que separa os âmbitos da ciência e da filosofia, legando a esta última o espaço da subjetividade. Para Kelsen, apenas o conteúdo circunscrito à ciência do direito, traduzida em termos de teoria do direito, poderia conferir ao fenômeno jurídico uma análise objetiva: a filosofia, e com muito mais razão a filosofia moral, não satisfaria essa exigência.

No entanto, é importante perceber que Kelsen rejeita completamente uma saída empirista - que, aparentemente, seria decorrência natural de uma concepção pautada na diferenciação entre mundo interior e mundo exterior - e nega que o direito deva ser imediatamente identificado com fatos brutos e exteriores. Afinal, e esse é o raciocínio construído por Kelsen, uma norma jurídica não tem a sua existência submetida a uma confirmação com aquilo que se passa no mundo exterior, de tal maneira que, por exemplo, o dever jurídico de "não roubar" não deixa de existir se alguém infringe essa regra. Pensar de modo diferente seria o mesmo que afirmar a impossibilidade de os enunciados jurídicos descreverem qualquer fato real, embora esse fato real não implique necessariamente um fato bruto do mundo exterior.

Por outro lado, a despeito de afirmar que o direito não se reduz aos fatos do mundo exterior, Kelsen também se nega a aceitar que os enunciados jurídicos não sejam dotados de conteúdo cognitivo. Para Kelsen, a emancipação do direito enquanto ciência - diferente, a título ilustrativo, da sociologia, que trabalha diretamente com os fatos empíricos - somente se dará demonstrando que os atos jurídicos de coerção em uma sociedade possuem, sim, um conteúdo cognitivo, embora diferente daquele presente nos objetos estudados pelas ciências naturais. Como sintetizou Cláudio Michelon Jr. (2004, p. 102): “o problema que persiste é: como tornar objetivo algo que não ocorre no mundo exterior".

Kelsen se propõe a retraduzir a ideia da objetividade e o faz nos termos da noção de validade. Desse modo, a existência objetiva de uma norma jurídica se verifica não por dados sensíveis perpetrados por meio de fatos do mundo exterior, mas pela atribuição de uma obrigatoriedade a determinados atos de vontade (KELSEN, 1998, p. 215). Esse caráter vinculativo, por sua vez, somente é atribuído por meio de outra norma igualmente válida, porém superior àquela. Tal escalada da validade levará inevitavelmente ao problema da "norma última" ou "norma fundamental" do ordenamento jurídico, ou seja, aquela em que a cadeia de validação termina. Para os presentes fins, basta perceber que a pretensão de objetividade moderna estava fortemente presente em Kelsen quando da delimitação do material de estudo da ciência do direito, ainda que sob uma roupagem completamente nova. 
Por outro lado, a reivindicação de objetividade também se faz sentir, no positivismo kelseniano, por meio de um outro aspecto estritamente ligado ao raciocínio anterior: justamente por ser passível de conhecimento objetivo, o direito não depende de qualquer sistema de justificação moral para ser considerado válido. Assim, não deve interessar ao jurista, no seu trabalho científico, a investigação da compatibilidade entre direito e moral, restando abolida a tese da unidade, tão cara aos jusnaturalistas. A esse respeito, ilustra Gabriel Nogueira Dias (2010, p. 148):

[...] mesmo que o legislador tenha posto uma determinada lei por convicção moral (por exemplo, por convicções cristãs ou islâmicas o legislador vota uma lei que proíbe ou permite a prática da poligamia), essa norma vale dentro do ordenamento jurídico, mas não por causa dos valores morais que a motivaram. Eles são irrelevantes para a constatação da validade pelo jurista. O mesmo vale para a supressão dessa norma, que não pode ser fundamentada numa concepção moral contrária, mas somente nos procedimentos de derrogação do ordenamento jurídico positivo em questão.

Por essa razão, aliás, Norberto Bobbio (1995, p. 135) afirma que o positivismo jurídico exige uma "abordagem avalorativa do direito", isto é, despida de qualquer juízo de valor. Não caberia à ciência do direito uma tomada de posição frente à realidade, mas uma tomada de conhecimento em face dela ${ }^{10}$ - ainda que, conforme visto, essa realidade não diga respeito a fenômenos empíricos, mas a fenômenos normativos. ${ }^{11}$

Essa exigência de uma abordagem avalorativa e científica por parte de Kelsen, contudo, se justifica pelo fato de que ele concebe que os valores não têm lugar no âmbito da investigação científica, por serem todos subjetivos e relativos. Em outros termos, embora, de modo geral, não haja uma relação teórica necessária entre positivismo e relativismo, na obra de Kelsen aquele é produto natural deste. Pelo fato de que o positivismo jurídico em Kelsen tem

Nesse sentido, sintetiza Kelsen (2001, p. 349-350): “Enunciados científicos são juízos sobre a realidade; por definição, são objetivos e independentes de desejos e temores do sujeito que julga porque são verificáveis por meio da experiência. São verdadeiros ou falsos. Juízos de valor, porém, têm caráter subjetivo porque são baseados, em última análise, na personalidade do sujeito que julga, em geral, e no elemento emocional de sua consciência, em particular".

11 A respeito do conceito de realidade, o próprio Kelsen (2001, p. 349-350) afirma: "Portanto, a afirmação de que normas são o objeto da ciência do direito não significa que o objeto dessa ciência não seja a realidade. Significa apenas que esse objeto não é uma realidade natural tal como descrita pela ciência natural. A diferença entre a realidade natural e a realidade jurídica é que a realidade jurídica, tal como descrita pela ciência jurídica, consiste em fatos que têm - contanto que seja pressuposta a validade da norma fundamental, não positiva - um significado específico: o significado de normas positivas”. 
raízes no relativismo moral é que em sua teoria jurídica ele se furta, por exemplo, a desenvolver uma análise abrangente a respeito do tema da interpretação judicial: porque a sua ciência do direito não comporta um ideal de objetividade moral, já que está assentada sobre o terreno da desconfiança em relação ao conceito de razão prática, ou seja, acerca da existência de um método racional capaz de orientar as pessoas a escolherem como agir. Eis o motivo pelo qual Kelsen (2001, p. 23) enuncia:

Se existe algo que a história do conhecimento humano nos pode ensinar é como têm sido vãos os esforços para encontrar, por meios racionais, uma norma absolutamente válida de comportamento justo, ou seja, uma norma que exclua a possibilidade de também considerar um comportamento contrário como justo.

Para Kelsen, “o ser humano conhece pela razão e age pela vontade” (BARZOTTO, 2017, p. 12). Desta feita, ao reconhecer que em todo ato de aplicação da lei existe um grau de indeterminação que demanda uma atividade interpretativa por parte do juiz, Kelsen também reconhece que dessa margem de interpretação - a famosa moldura normativa decorre um ato de criação do direito que não está sujeito a uma teoria objetiva da moralidade, tampouco da racionalidade, mas à discricionariedade do aplicador:

[...] na aplicação do direito por um órgão jurídico, a interpretação cognoscitiva (obtida por uma operação de conhecimento) do direito a aplicar combina-se com um ato de vontade em que o órgão aplicador do direito efetua uma escolha entre as possibilidades reveladas através daquela mesma interpretação cognoscitiva. (KELSEN, 1998, p. 394)

Não é por acaso que Kelsen recomenda expressamente que a linguagem legal e constitucional seja a mais clara possível, com a menor margem para apreciações de tipo valorativo. Ao recomendar o afastamento de princípios do texto normativo, Kelsen não estava simplesmente sendo fiel ao seu ideal de "pureza” jurídica - mesmo porque essa pureza não se relaciona ao conteúdo das normas jurídicas, mas ao exercício da ciência do direito. Sobretudo, conforme veremos no tópico a seguir, Kelsen estava sendo defensor da democracia parlamentar, pois efetivamente não desejava que o Poder Judiciário ocupasse a posição de criador normativo, o que apresentaria um grande problema ao seu ideal democrático - também fundado, por sua vez, no relativismo.

\subsection{O RELATIVISMO NA TEORIA DA DEMOCRACIA}

Neste ponto, começamos uma transição do relativismo moral tal como incorporado no campo jurídico para o relativismo moral tal como foi aplicado ao campo da política. Aqui, é interessante perceber, inicialmente, que Kelsen sempre se mostrou desejoso de aplicar a sua concepção normativista formal a uma epistemologia geral das ciências sociais, notadamente no 
tocante ao órgão social por excelência, que é o Estado (HERRERA, 2010, p. 100). Ao conceber o Estado tão somente como uma ordem normativa centralizada (KELSEN, 1945, p. 189), Kelsen nada mais faz do que situar o estudo do Estado como um viés da teoria do direito, ${ }^{12}$ retirando-o do âmbito da ciência política. ${ }^{13}$ Assim, o próprio conceito de ciência política começa a se delinear, na obra kelseniana, a partir de uma exclusão: se a teoria do Estado, enquanto pertencente ao espectro mais amplo da teoria jurídica, deve se ocupar daquilo que o Estado é, bem como do modo como ele é, à teoria política cabe se ocupar da questão sobre se o Estado deve existir em geral e qual a melhor forma de Estado (HERRERA, 2010, p. 106).

Contudo, precisamente neste ponto pode surgir uma dúvida: o estudo acerca da melhor forma de Estado não implica, por si só, um juízo de valor subjetivo, que descaracteriza o próprio caráter científico que Kelsen - em sua lealdade ao projeto moderno - pretende dar ao estudo da política? Como se abster de realizar juízos de valor em uma ciência cujo próprio objeto está impregnado de juízos de valor?

A saída que Kelsen dá a esses questionamentos é bastante interessante, porque aqui ele percebe a singularidade do objeto da ciência política em relação ao objeto da ciência do direito: para Kelsen, não é a metodologia da imputação (tal como ocorre no direito) que rege a ciência política, mas sim a metodologia da causalidade. A fim de explicitar melhor essa diferença e o papel do relativismo na teoria política de Kelsen, é necessário fazer uma pequena digressão acerca do que Kelsen entende por imputação e causalidade.

Para Kelsen, a imputação consiste "no significado específico da ligação entre condição e consequência, estabelecida por uma norma jurídica (uma prescrição ou permissão)" (KELSEN, 2001, p. 362). Como o objeto da ciência do direito não é uma realidade natural, mas uma realidade constituída por normas positivas, os enunciados pelos quais o cientista do direito descreve seu objeto não são uma aplicação do princípio da causalidade, este entendido como uma relação necessária ou provável de causa-efeito, mas obedecem a um outro critério, precisamente o da imputação. A relação, neste caso, é de condição e consequência, interligadas por um dever, como na seguinte sentença: "se um homem comete um roubo,

12 Em sua autobiografia, Eric Voegelin, que fora discípulo de Kelsen e, no entanto, se tornou um dos maiores defensores de uma teoria do direito natural duramente rebatida por Kelsen, explica: "Era obviamente impossível lidar com os problemas do Staat - e da política em geral - omitindo tudo, menos a lógica jurídica. Minha divergência com Kelsen se desenvolveu, portanto, a partir de meu interesse pelas fontes de uma ciência política que fora excluída da Staatslehre entendida como Rechtslehre”. Com Voegelin, aliás, Kelsen tem um extenso debate em torno do livro A nova ciência da política, escrito pelo primeiro. O livro que Kelsen dedicou a rebater a obra voegeliana foi publicado apenas em 2004. Vide Kelsen (2006).

13 Aqui, Kelsen vai na contramão da tradição jurídico-política da Alemanha, que situava essa temática no interior da ciência política, denominada Staatswissenschaften (HERRERA, 2010, p. 106). 
outro homem deve puni-lo". O dever, aqui, se reveste de um caráter objetivo, pois o homem que deve punir o ladrão é obrigado a fazê-lo independentemente de seu desejo: ele deve fazê-lo pelo simples fato de que uma norma jurídica válida - ou seja, objetiva no sentido kelseniano - o prescreve.

Ocorre que a esta altura a questão começa a se complicar, porque também a ciência política tem como objeto um conjunto de normas que, neste caso, não são jurídicas, mas têm natureza moral; a diferença é que o dever-ser, isto é, o conjunto normativo que constitui o objeto da ciência política não tem um caráter objetivo, mas um caráter subjetivo. Por exemplo: quando alguém afirma que a democracia é a melhor forma de governo porque ela permite ao ser humano alcançar o máximo grau possível de liberdade, esse alguém está pressupondo, subjetivamente, que a liberdade é um valor supremo com pretensão de validade universal o advérbio "subjetivamente", aqui, se deve ao próprio fato de que, para um relativista como Kelsen, a referência a um valor absoluto só pode se tratar de uma experiência completamente pessoal, não objetivável.

No cenário descrito anteriormente, caberia ao cientista político analisar de maneira objetiva o quadro de valores subjetivos. Em outros termos, ao cientista político, no exercício de seu fazer científico, não caberia julgar como bom ou mau o valor supremo atribuído por aquele que defende uma dada forma de governo, mas se perguntar, por exemplo: se o fim (valor supremo) é a liberdade, de fato a democracia é o meio mais adequado para alcançá-lo? Ou, ainda: se o valor supremo é a segurança econômica, o comunismo é verdadeiramente o meio para obtê-lo? Perceba-se que neste caso o cientista político não analisa o fim supremo, mas o meio proposto para obter esse fim. Trata-se de uma abordagem interna, analítica. A garantia de objetividade do cientista político é, portanto, a aplicação da metodologia da causalidade.

Assim, aplica-se à ciência política a teoria da causalidade, e não a teoria da imputação, pelo simples fato de que o teste de adequação entre meio e fim pode ser feito a partir da experiência e é suscetível de ser comprovado na realidade dos fatos brutos (HERRERA, 2010 , p. 112). Desta feita, se, por um lado, o próprio fim pressuposto - a liberdade ou a segurança econômica, por exemplo - não tem sua validade passível de comprovação pela ciência, a análise meio e fim é totalmente passível de uma investigação científica que lance mão da metodologia adequada. Trata-se, portanto, de uma clara abordagem empírica, embora o objeto dessa abordagem consista em um sistema de valores normativos constituído pelas autoridades políticas. Aqui fica evidente que Kelsen também elaborou uma espécie de teoria do conhecimento político a exemplo do que fez com o direito: a empreitada jurídica de Kelsen se pretende anti-ideológica, assim como a sua própria empreitada na ciência política.

O grande questionamento que se põe a partir deste ponto diz respeito, naturalmente, ao papel da democracia dentro da ciência política que Kelsen buscou empreender: em sua abordagem da democracia, estaria Kelsen defendendo essa forma de governo e, com isso, contradizendo seu relativismo moral e, portanto, sua pretensão de uma ciência política objetiva? 
Inicialmente, poder-se-ia objetar que a postulação kelseniana de aplicação da metodologia da causalidade à ciência política não incidiria sobre seus primeiros estudos da democracia, pelo fato de que tal tentativa de objetivação do tratamento da política só foi realizada durante aquilo que Herrera chama de período tardio da teoria política de Kelsen, a partir do final da década de 1940. ${ }^{14}$ Assim, ensaios como Essência e valor da democracia - cuja primeira edição é datada de 1920 e a segunda, de 1929 - não estariam ainda imbuídos de uma tal metodologia a partir desse raciocínio.

Contudo, essa suposição não é correta, pois a tentativa de Kelsen em apresentar uma metodologia própria para a ciência política não é incompatível com as suas primeiras produções acerca da democracia. Isso se percebe por duas razões: inicialmente, porque já em sua produção inicial da década de 1920, Kelsen utilizava precisamente o método da causalidade para analisar as diversas formas de governo ${ }^{15} \mathrm{em}$ segundo lugar, porque na sua obra Fundamentos da democracia, de 1955, Kelsen não altera em praticamente nada o seu tratamento a respeito da democracia e da autocracia, demonstrando que a aplicação da metodologia da causalidade não é em nada incompatível com a abordagem que fizera já na década de 1920 .

Sendo assim, como compatibilizar a aparente defesa kelseniana da democracia, que transparece em suas análises teóricas, com a sua defesa de uma metodologia científica e objetiva para a teoria política? Será verdade que, em sua abordagem do fenômeno democrático, Kelsen extrapola suas próprias recomendações metodológicas? (VENERIO, 1999, p. 66) A resposta

Para falar especificamente, o artigo em que Kelsen trabalha de maneira mais pontual a aplicação da metodologia causal à ciência política foi publicado em 1951 na American Political Science Review, sob o título original de Science and Politics.

15 Como exemplo desse fato, observe-se a análise que Kelsen realiza a respeito da ideia de democracia social adotada pelos regimes marxistas já em Essência e valor da democracia. Nela, fica evidente a crítica em termos de método, hipótese e postulados: "À primeira vista, parece muito estranho que, exatamente para a realização da ideia socialista, o método democrático seja alijado, já que o socialismo, desde Marx e Engels, parte da hipótese - até agora de importância capital para a sua doutrina não só política, mas também econômica - de que o proletariado explorado e depauperado constitui a imensa maioria da população e que lhe basta tomar consciência da própria situação de classe para que ele se organize no partido socialista e daí se prepare para uma luta de classes contra uma minoria ínfima. E o socialismo pôde lutar pela democracia justamente porque se sentia seguro de conquistar o poder através da lei da maioria. Mas o aparecimento das democracias burguesas na primeira metade do século XIX e, ainda mais, a sua longa duração e a sua evolução democrática progressiva já não se conciliavam tanto com os postulados do socialismo. Por que, então, a democracia puramente política não se torna também econômica, ou seja, porque o grupo dominante é burguês-capitalista e não proletário-comunista, se proletariado educado na mentalidade socialista constitui a maioria e se o sufrágio universal e igualitário garante à maioria a supremacia no Parlamento? Naturalmente, a pergunta acima vale apenas para os países em que há verdadeira democracia, onde existem incontestáveis universalidade e igualdade de direitos políticos" (KELSEN, 2000, p. 100-101). 
para tanto parece residir precisamente no fato de que a própria democracia está intimamente atada à defesa que Kelsen realiza da metodologia científica.

É bem verdade que Kelsen, enquanto homem político, tinha suas preferências ideológicas. Ele próprio não o nega, como revela essa passagem de sua autobiografia: "pessoalmente, tenho toda simpatia por um partido socialista e ao mesmo tempo democrático, e nunca dissimulei essa simpatia” (KELSEN, 2012, p. 71). Entretanto, logo em seguida o próprio Kelsen (2012, p. 71) assevera:

Porém, mais forte de que essa simpatia era e é minha necessidade de independência partidária na minha profissão. O que eu não concedo ao Estado - o direito de limitar a liberdade da pesquisa e da expressão do pensamento - eu não posso conceder a um partido político por meio da submissão voluntária à sua disciplina.

Desse rigor científico no tratamento dos seus objetos de estudo, Kelsen era particularmente consciencioso, como aponta Matthias Jestaedt (2010, p. 173). Havia uma clara divisão de papéis entre o Kelsen teórico e o Kelsen "homem-dotado-de-preferências-políticas" e essa cisão se faz perceber em suas abordagens da democracia, da qual não realiza uma defesa direta, mas uma análise objetiva (de causa e efeito) enquanto fenômeno social (HERRERA, 2010, p. 119). A princípio, a sua abordagem da democracia deve ser vista tão somente como parte integrante de um quadro investigativo maior, consistente em uma abordagem científica acerca das formas de Estado. Nesse cenário, destaque-se, não só a democracia foi objeto de análise, mas também as autocracias.

Ocorre que a abordagem científica e racionalista de Kelsen tem repercussões não apenas no plano teórico, mas reverbera na sua tomada de posições políticas. Conforme elucida Jestaedt (2010, p. 179), a ciência representava, para Kelsen, uma maneira específica de observar o mundo, produzindo, no sentido mais original do termo, uma verdadeira visão de mundo (Weltanschauung). Tal visão de mundo, por sua vez, só pode conduzir a uma única forma de governo: a democracia. ${ }^{16} \mathrm{Com}$ isso, a democracia converte-se no melhor regime para Kelsen não em razão de seu valor intrínseco - pois para um relativista como ele não existem meios cognitivos para alcançar tal compreensão -, mas pelo fato de que ela está em consonância com o projeto moderno para a ciência do direito e, consequentemente, também para a ciência política. A tomada de posição política de Kelsen em favor da democracia é, em suma, uma

16 A esse respeito, diz Kelsen em sua autobiografia: "Em 1920, foi publicada uma monografia minha Vom Wesen und Wert der Demokratie [A essência e o valor da democracia], na qual desenvolvi, entre outras ideias, a de que a ideologia democrática corresponde a uma concepção fundamental empírico-relativista, enquanto a tendência às formas autocráticas está relacionada a uma metafísico-absolutista” (KELSEN, 2012, p. 32). 
decorrência direta da ciência enquanto visão de mundo. Nesse mesmo sentido entende Olivier Jouanjan (2010, p. 200, tradução livre):

Essa é precisamente a razão profunda pela qual o cientista Kelsen, com todo o seu formalismo radical e seu objetivismo assumido, não se contenta em descrever a democracia, mas em tomar a sua defesa: o cientista não pode prescrever e não pode dizer: "você deve escolher a democracia”, mas ele poderá dizer, à maneira de Max Weber: "se você deseja esse fim, é necessário esse meio" (ele não pode enunciar um Sollen categórico, mas um Müssen hipotético). Se você deseja a ciência, o conhecimento e a compreensão do mundo, é necessário fazer a escolha pela democracia.

Aqui, o fundamento relativista da democracia se mostra com toda a sua clareza: a democracia é apresentada por Kelsen sempre como um procedimento técnico-racional, jamais um conteúdo determinado; ela é sempre um meio, jamais um fim, pois não representa a reprodução estática de uma vontade preexistente, mas sobretudo um processo que exprime a dinâmica da formação da vontade estatal, traduzida nos termos de um ordenamento jurídico. A esse respeito, sintetiza Kelsen (2000, p. 105):

Por isso, o relativismo é a concepção de mundo suposta pela ideia democrática. A democracia julga da mesma maneira a vontade política de cada um, assim como respeita igualmente cada credo político, cada opinião política cuja expressão, aliás, é a vontade política. Por isso a democracia dá a cada convicção política a mesma possibilidade de exprimir-se e de buscar conquistar o ânimo dos homens através da livre concorrência.

Dessa maneira, a epistemologia kelseniana de fato tem efeitos ético-políticos, mas ela própria é influenciada por um ponto de partida metaético, que é precisamente aquele que provém do relativismo. O contrário da atitude democrática, por sua vez, consiste em uma atitude autocrática, associada a uma concepção metafísico-absolutista (KELSEN, 2000, p. 105).

As específicas consequências desse ponto de partida relativista para a abordagem kelseniana acerca da democracia não serão abordadas neste artigo. Por enquanto, basta reafirmar que, para Kelsen, o relativismo assegura um terreno de livre concorrência e de igualdade de valores, de modo que o resultado desse ambiente, por assim dizer relativista, é um espaço de liberdade e de igualdade de direitos políticos, compatível unicamente com a democracia. Afinal, se a superioridade de um valor em relação a outro não pode ser atestada pela ciência política, a todos deve ser dada a igual possibilidade de participar da formação da ordem jurídica - ainda que, em virtude da existência de valores conflitantes, isso não seja possível a todos, ao menos em todos os momentos.

Nesse ponto, a crítica de Alfonso Ruiz Miguel, proferida na conferência de 2016 ¿Hay que ser relativista para ser democrático?, é bastante perspicaz. Para o autor espanhol, Kelsen teria 
confundido a relatividade da democracia com a justificação relativa da democracia. Isso porque, segundo Ruiz Miguel, embora a democracia de fato consista em um procedimento pelo qual as decisões axiológicas são temporárias e relativas (já que passíveis de modificação posterior pela regra da maioria), ${ }^{17}$ a justificação da democracia, isto é, os critérios pelos quais ela é adotada não são em si relativos: ao contrário, o valor da autonomia individual, do pluralismo ideológico e da necessidade de proteger os direitos básicos seriam critérios considerados moralmente corretos e objetivos, inclusive pelo próprio Kelsen. Segundo Ruiz Miguel (2016, p. 13, tradução livre):

[...] quem, como Kelsen, defende como superiores os valores da liberdade e tolerância próprios dos sistemas democráticos não está mantendo uma concepção desportiva da política, indiferente à vitória da democracia ou do totalitarismo. Se sua convicção democrática é forte, não pode sustentar que o totalitarismo seja tão correto como a democracia, de modo que considere correto que ganhe o mais forte.

Como resultado, diz Alfonso Ruiz Miguel, o suposto relativismo kelseniano deveria ser entendido não como uma espécie de combate a uma pretensão de objetividade axiológica, mas como um ataque a uma pretensão de falibilidade. Em outros termos, Ruiz Miguel afirma que o relativismo kelseniano não seria genuíno, pois os valores democráticos da liberdade e tolerância são defendidos por Kelsen de maneira objetiva, embora sem pretensão de serem infalíveis, ou seja, de serem rechaçados mediante uma discussão racional. Em suma, para Ruiz Miguel, o relativismo de Kelsen não representaria uma amostra legítima dessa concepção filosófica, mas tão somente um afastamento da "crença dogmática ou fundamentalista de que nosso juízo moral é verdadeiro sem possibilidade de revisão nem refutação alguma” (RUIZ MIGUEL, 2016, p. 18).

No entanto, será mesmo assim? A despeito de o argumento fazer sentido, Alfonso Ruiz Miguel parece ter ignorado o detalhe apontado por Herrera e Jestaedt, ${ }^{18}$ e reafirmado neste trabalho, segundo o qual a atividade de Kelsen enquanto cientista político seria a de analisar as diversas formas de governo a partir de uma metodologia da causalidade. Conforme o próprio Kelsen explicou, ao cientista político não está vedado eleger uma determinada forma de governo como a melhor, sendo que a questão decisiva é como ele o faz. Nesse sentido:

17 Alfonso Ruiz Miguel se alinha expressamente ao conceito procedimental de democracia defendido por Bobbio - que, por sua vez, também foi fortemente influenciado por Kelsen.

18 Vide Jouanjan (2010). 
O enunciado de que algo é um meio adequado para um fim é verdadeiro ou falso; para ser verdadeiro, deve ser verificável pela experiência. Se o enunciado de que uma organização comunista é "boa" significa apenas que é um meio adequado de ocasionar segurança econômica para todos, e se o enunciado de que uma organização capitalista é "má" significa apenas que ela não tem esse resultado, nenhum dos dois em si é um juízo de valor no sentido específico do termo. Ambos são juízos sobre a realidade, e, se são classificados como juízos de valor, tais juízos de valor não são diferentes de juízos sobre a realidade, mas apenas um tipo especial de tais juízos, e, portanto, não devem ser excluídos da esfera da ciência. (KELSEN, 2001, p. 351)

Desta feita, para Kelsen, fortemente influenciado por Max Weber, ${ }^{19}$ ao cientista político está vedado eleger um determinado fim como o superior, mas apenas analisar o fim que a autoridade política elegeu e verificar se os meios empregados são adequados a esse fim, de forma que apenas assim à ciência política é dado classificar uma forma de governo como correta ou incorreta.

Além do mais, o pluralismo ideológico e a necessidade de proteger os direitos básicos não são para Kelsen valores superiores por si mesmos, mas valem enquanto características intrínsecas ao mecanismo democrático de tomada de decisões. Em suma: são eles próprios mecanismos. Desse modo, se para Kelsen o resultado da democracia pode ser um ambiente de

19 A influência de Max Weber na obra de Kelsen é expressamente reconhecida pelo próprio jurista. Norberto Bobbio lembra que Kelsen cita Weber no prefácio de sua primeira grande obra de 1911, incluindo a afirmação weberiana acerca de um fim cognitivo puramente formal das normas jurídicas como o núcleo central de sua teoria (BOBBIO, 2008, p. 218). Elucidando a posição de Weber acerca de uma ciência social livre de valores, Eric Voegelin faz um resumo que poderia facilmente dizer respeito ao tipo de abordagem que Kelsen assume acerca da ciência política: "Uma ciência livre de valores significava para Weber a exploração de causas e efeitos, a construção de tipos ideais que permitiriam distinguir a regularidade das instituições assim como os desvios dela, e especialmente a construção de relações causais típicas. Tal ciência não poderia estar na posição de dizer a alguém se deveria ser um liberal econômico ou um socialista, um constitucionalista democrático ou um revolucionário marxista, mas poderia dizer-lhes as consequências se ele desejasse traduzir os valores de sua preferência em prática política. De um lado, havia os valores da ordem política além da avaliação crítica; do outro lado, havia a ciência da estrutura da realidade social que deveria ser usada como conhecimento técnico por um político. Ao abordar a questão de uma ciência 'livre de valores' a partir desse ponto de vista pragmático, Weber deslocou o debate das disputas metodológicas novamente para a ordem de relevância. Ele desejava a ciência porque ele queria claridade sobre o mundo em que apaixonadamente participava; ele estava novamente a caminho da essência. A busca pela verdade, no entanto, foi reduzida ao nível da ação pragmática. No clima intelectual do debate metodológico, os valores deveriam ser considerados inquestionáveis, e a busca não poderia avançar em direção à contemplação da ordem. A ratio da ciência não se estendia, para Weber, até os princípios, mas apenas até a causalidade da ação" (VOEGELIN, 2000, p. 98, tradução livre). 
paz e tolerância, somente é assim porque a democracia se fundamenta no relativismo, e não o inverso:

Se, em um caso concreto, a ordem social não for criada de um modo que corresponda a essa definição ou não contenha as garantias de liberdade, não é porque a democracia não está a serviço dos ideais. Os ideais não são atendidos porque a democracia foi abandonada. (KELSEN, 1955, p. 4)

Nesse sentido, o que se tem é a epistemologia (relativismo) constituindo a identidade do objeto (democracia).

\section{Conclusão}

A essência da crítica formulada de Alfonso Ruiz Miguel tem grande valor se desdobrada em uma outra possibilidade de objeção: a de que, para Kelsen, o relativismo se transforma em um valor superior em si mesmo, consistente na "expressão política da igual liberdade das vontades" (LEPSIUS, 2010, p. 168).

Em outros termos, a pureza propugnada por Kelsen, seja em sua teoria do direito, seja em sua teoria política - e teoria política é o equivalente semântico de ciência política -, passa a denotar um valor por si mesma. Trata-se da pureza científica como visão de mundo, como já assentado por Jestaedt. Como consequência, o valor da democracia, para Kelsen, consiste na sua ausência de conteúdos fundantes, o que a permite funcionar como uma engrenagem para a produção e expressão permanente da pluralidade dos valores em concorrência, inclusive daqueles que vão contra a própria essência da democracia. ${ }^{20}$

Desse modo, a pureza científica converteu-se para Kelsen em um valor per se, ao mesmo tempo que seu caráter emancipatório se mostrou como uma via de mão dupla: ao conferir autonomia metodológica ao direito e à política, Kelsen nutria a esperança de que o próprio labor científico fosse protegido.

Enquanto legítimo herdeiro da filosofia moderna, Kelsen acreditava, como Descartes, em um método redentor, capaz de se converter em uma lente através da qual fosse possível observar a realidade. Trata-se, conforme explicou Jestaedt, da ciência como visão do mundo. ${ }^{21}$

20 Nas palavras de Kelsen (2000, p. 31): “o fato de poder eliminar-se a si própria através de seus métodos específicos de formar a vontade do Estado constitui o privilégio paradoxal dessa forma de governo e uma duvidosa vantagem sobre a autocracia”.

21 A esse respeito, vide Jestaedt (2010). 
Na obra de Kelsen, a cientificidade passou a ser o critério de legitimação do conhecimento do direito e da política e, quanto tal, moldou esses objetos. Não apenas a ciência da política e do direito, mas também o direito e a política foram destituídos de todo conteúdo extrínseco. Não se fazia mais possível conceber as ideias de Estado, pessoa, povo e moralidade fora dos paradigmas estabelecidos pela própria ciência, já que nada podia ser pensado como preexistente a ela. Com isso, o relativismo moral tornou-se a expressão filosófica da pureza científica.

Nesse sentido, a ciência teria se tornado a verdadeira emancipadora dos homens, libertando o direito e a política daquilo que Kelsen chamava de interesses poderosos (KELSEN, 2001, p. 25). O caminho rumo à liberdade seria, desse modo, pavimentado pelo método. Mas para onde leva esse caminho? O que é essa liberdade? Em que consiste essa autodeterminação? Neste ponto, não estamos mais no terreno da cognição científica. A resposta kelseniana para esse derradeiro questionamento está na irracionalidade. Fora da ciência não se encontrará nada mais do que desejos inconscientes, sentimentos e preferências pessoais. Os problemas dessa perspectiva, entretanto, são tema para outro trabalho.

\section{AGRADECIMENTOS}

A autora agradece o apoio financeiro da Coordenação de Aperfeiçoamento de Pessoal de Nível Superior (Capes).

\section{REFERÊNCIAS}

BARZOTTO, Luis Fernando. Teoria do direito. Porto Alegre: Livraria do Advogado, 2017.

BOBBIO, Norberto. O positivismo jurídico: lições de filosofia do direito. Tradução de Márcio Pugliesi, Edson Bini e Carlos E. Rodrigues. São Paulo: Ícone, 1995.

BOBBIO, Norberto. Direito e poder. Tradução de Nilson Moulin. São Paulo: Editora UNESP, 2008.

DIAS, Gabriel Nogueira. Positivismo jurídico e a teoria geral do direito: na obra de Hans Kelsen. São Paulo: Revista dos Tribunais, 2010.

DWORKIN, Ronald. Justiça para ouriços. Tradução de Pedro Elói Duarte. Coimbra: Almedina, 2012. 
FERRAJOLI, Luigi. La logica del diritto: dieci aporie nell'opera di Hans Kelsen. Roma: Laterza, 2016.

HERRERA, Carlos Miguel. Théorie juridique et politique chez Hans Kelsen. Paris: Éditions Kimé, 1997.

HERRERA, Carlos Miguel. Science et politique chez Hans Kelsen. In: JOUANJAN, Olivier (org.). Hans Kelsen: forme du droit et politique de l'autonomie. Paris: Presses Universitaires de France, 2010.

JESTAEDT, Matthias. La science comme vision du monde. In: JOUANJAN, Olivier (org.). Hans Kelsen: forme du droit et politique de l'autonomie. Paris: Presses Universitaires de France, 2010.

JOUANJAN, Olivier (org.). Hans Kelsen: forme du droit et politique de l'autonomie. Paris: Presses Universitaires de France, 2010.

KELSEN, Hans. General theory of law and state. Cambridge: Harvard University Press, 1945.

KELSEN, Hans. Foundations of democracy. Ethics, v. 66, n. 1, p. 1-101, 1955.

KELSEN, Hans. Problemi fondamentali della dottrina del diritto pubblico: esposti a partire dalla dottrina della proposizione giuridica. Tradução italiana de Agostino Carrino e Giuliana Stella. Napoli: Edizioni Scientifiche Italiane, 1997.

KELSEN, Hans. Teoria pura do direito (edição de 1960). Tradução de João Baptista Machado. São Paulo: Martins Fontes, 1998.

KELSEN, Hans. Essência e valor da democracia (edição de 1929). In: KELSEN, Hans. A democracia. Tradução de Ivone Castilho Benedetti, Jefferson Luiz Camargo, Marcelo Brandão Cipolla e Vera Barkow. São Paulo: Martins Fontes, 2000.

KELSEN, Hans. O que é justiça? A justiça, o direito e a política no espelho da ciência. Tradução de Luís Carlos Borges. São Paulo: Martins Fontes, 2001.

KELSEN, Hans. ¿Una nueva ciencia de la política?: Réplica a Eric Voegelin. Tradução espanhola de Isolda RodríguezVillegas e Joaquín Etorena. Buenos Aires: Katz, 2006.

KELSEN, Hans. Autobiografia de Hans Kelsen. Tradução de Gabriel Nogueira Dias e José Ignácio Coelho Mendes Neto. Rio de Janeiro: Forense Universitária, 2012.

LEPSIUS, Olivier. Kelsen, théoricien de la démocratie. In: JOUANJAN, Olivier (org.). Hans Kelsen: forme du droit et politique de l'autonomie. Paris: Presses Universitaires de France, 2010. p. 135-170. 
MICHELON JR., Cláudio For tunato. Aceitação e objetividade: uma comparação entre as teses de Hart e do positivismo precedente sobre a linguagem e o conhecimento do direito. São Paulo: Revista dos Tribunais, 2004.

PECORA, Gaetano. Introdução ao pensamento político de Hans Kelsen. Curitiba: Juruá, 2015.

PEREIRA, Oswaldo Porchat. Ceticismo e mundo exterior. Discurso, n. 16, p. 33-68, 1987.

REALE, Giovanni; ANTISERI, Dario. História da filosofia: Antiguidade e Idade Média. São Paulo: Paulus, 1990.

RUIZ MIGUEL, Alfonso. Semana Norberto Bobbio. Conferência ¿Hay que ser relativista para ser democrático? São Paulo, 2016.

SCRUTON, Roger. Uma breve história da filosofia moderna: de Descartes a Wittgenstein. Tradução de Eduardo Francisco Alves. Rio de Janeiro: José Olympio, 2008.

VENERIO, Carlos Magno Spricigo. A concepção de democracia de Hans Kelsen. 1999. Dissertação (Mestrado) Universidade Federal de Santa Catarina, Florianópolis, 1999.

VOEGELIN, Eric. Modernity without restraint. The collected works of Eric Voegelin. Columbia: University of Missouri Press, 2000. v. 5.

WHITEHEAD, Alfred North. A ciência e o mundo moderno. Tradução de Hermann Herbert Watzlawick. São Paulo: Paulus, 2006.

\section{COMO CITAR ESTE ARTIGO:}

BRAGA, Ana Luiza Rodrigues. Relativismo moral em Kelsen: do juspositivismo à democracia. Revista Direito GV, v. 16, n. 2, maio/ago. 2020, e1958. doi: http://dx.doi.org/10.1590/ 2317-6172201958.
Ana Luiza Rodrigues Braga

Mestre e Doutoranda em Filosofia e Teoria Geral do Direito pela Universidade de São Paulo (USP). Professora dA Universidade SÃo Judas. DiRETORA Acadêmica do INSTITUTO IVES GANDRA. analuizarodrigueslausp.br 